\title{
Flexibacter canadensis sp. nov.
}

\author{
PENELOPE CHRISTENSEN \\ Department of Soil Science, University of Alberta, Edmonton, Alberta T6G 2E9, Canada
}

University of Alberta Soil Microbiology strain 9D is a gram-negative, nonflagellated, gliding, white, facultatively anaerobic, non-polysaccharolytic, long, thin rod or filament. The guanine plus cytosine content of the deoxyribonucleic acid of this strain is $37.0 \mathrm{~mol} \%$. This strain belongs to the genus Flexibacter, but it differs significantly from strains of previously described species. Therefore, it is regarded as belonging to a new species, for which the name Flexibacter canaden. sis is proposed. A culture of the type strain, 9D, has been deposited in the American Type Culture Collection under the number 29591.

The purpose of this paper is to describe the properties of a gliding, non-polysaccharolytic bacterium, strain 9D, and to determine its taxonomic position.

\section{MATERIALS AND METHODS}

Bacterial strain. University of Alberta Soil Microbiology (UASM) strain 9D was isolated from soil by F.D. Cook, and a culture of this strain has been deposited in the American Type Culture Collection (ATCC), Rockville, Md., under the number ATCC 29591.

Media and methods. The media and methods used to characterize this organism have been described previously $(1,3)$.

\section{RESULTS}

The characteristics of strain $9 \mathrm{D}$ are as follows.

Cell morphology. Gram-negative, nonflagellated, flexible, thin rods or filaments measuring 0.3 by 3 to $60 \mu \mathrm{m}$ (Fig. 1) and showing gliding motility and good spreading ability on many dilute media such as Cook cytophaga agar and skim milk-acetate agar.

Cultural characteristics. Cook cytophaga agar: 5-Day-old colonies are white with a pale blue-green iridescence, irregular with a rough surface and lobate edge, and effuse and transparent with no water-soluble pigment. The Munsell color of the colonies is 2.5 Y $8 / 2$.

Skim milk-acetate agar: 5-Day-old colonies are whitish with a blue-green iridescence, irregular with a rough surface and lobate edge, and effuse and transparent to opaque with no watersoluble pigment. The Munsell color of the colonies is 10 YR 8/2.

Plate count agar: 5-Day-old colonies are very pale pinkish gray with a blue-green iridescence, irregular with a smooth surface and lobate edge, effuse to raised and translucent to opaque with no water-soluble pigment. The Munsell color of the colonies is $2.5 \mathrm{YR} 6 / 3$.
The Munsell colors observed on various media are 2.5 YR 6/3, 6 YR 6/4, 7.5 YR $6 / 4$ and $7 / 2$, 10 YR $7-8 / 2$ and $7 / 3$, and 2.5 Y 7-8/2; no watersoluble pigment has ever been observed.

Broth culture: Overnight growth in a shaken culture is silky but not viscous or flocculent; there is no surface ring or pellicle produced.

Fruiting bodies and microcysts are not produced.

Physiology. Growth is reduced by $1 \%$ and is inhibited by $2 \% \mathrm{NaCl}$; the preferred atmosphere for growth is $10 \% \mathrm{O}_{2}$; the temperature range is 10 to $40^{\circ} \mathrm{C}$, optimum growth occurring at 18 to $30^{\circ} \mathrm{C}$; the $\mathrm{pH}$ range for growth is 5 to 10 , optimum growth occurring at pH 6 to 8 .

$\mathrm{NH}_{4}{ }^{+}$, glutamate, asparaginate, and various proteins and protein digests (e.g., tryptone, Casitone, gelatin, casein), but not $\mathrm{NO}_{3}{ }^{-}$or urea, are utilized as sole $N$ sources.

Growth is stimulated by yeast extract on media containing agar only or chitin and agar only.

Growth is not reduced by $0.01 \%$ but is inhibited by $0.1 \%$ sodium lauryl sulfate. The organism is susceptible to $30 \mu \mathrm{g}$ of chlorampheni$\mathrm{col}, 10 \mu \mathrm{g}$ of dihydrostreptomycin, $300 \mathrm{U}$ of

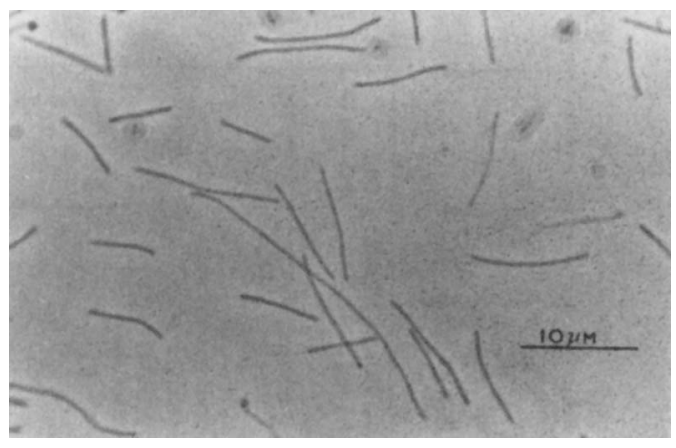

FIG. 1. Cells of strain UASM strain $9 D$. 


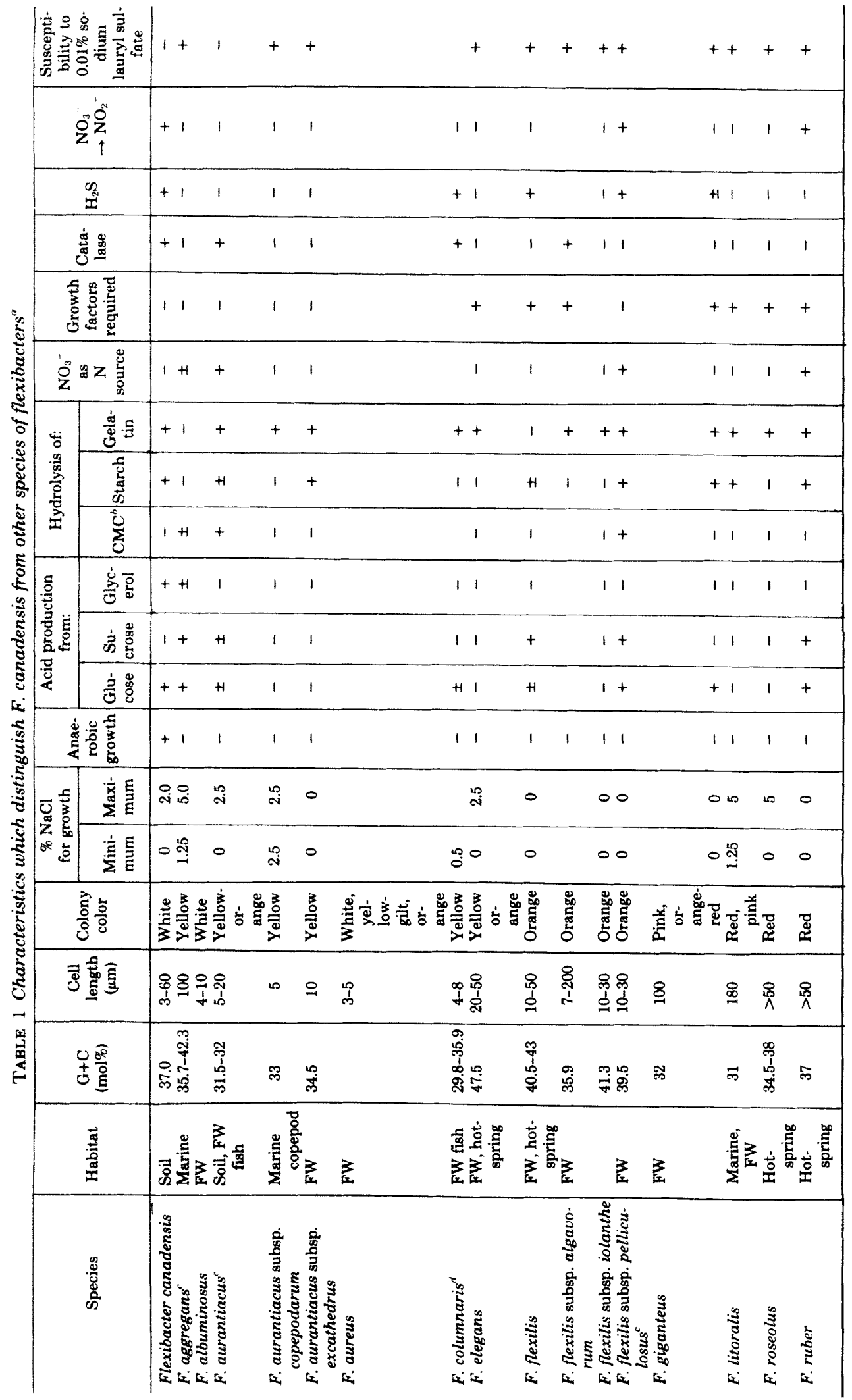




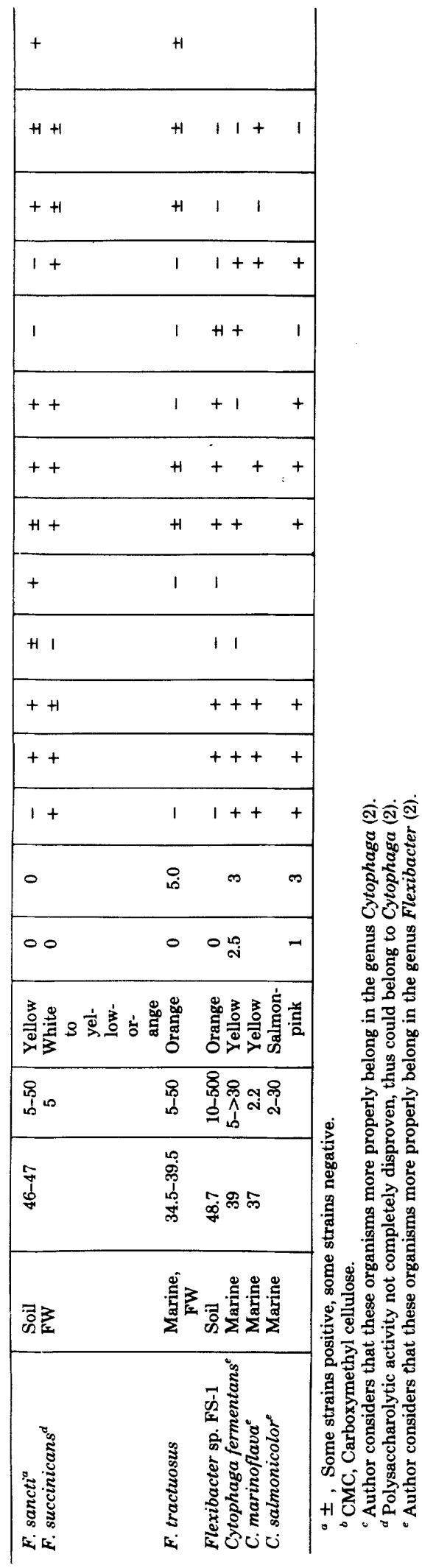

polymyxin $B$, and actinomycin $D$; it is resistant to $10 \mathrm{U}$ of penicillin.

Bacteria and fungi are not lysed, but the possible lysis of actinomycete strain UASM 4441 and of a Chlorella sp. culture was noted.

Biochemical reactions. The attack on glucose is both oxidative and fermentative. Acid is produced from lactose, glucose, cellobiose, and glycerol but not from sucrose or mannitol.

Lipolytic activity on tributyrin and on Tweens $20,40,60$, and 80 has not been detected.

Hydrolyzes starch; weakly hydrolyzes pectate; does not hydrolyze cellulose (filter paper or carboxymethyl cellulose), chitin, agar, or alginate.

Liquefies gelatin; peptonizes milk in 2 days; growth and $\mathrm{NH}_{3}$ produced from Casitone, casein, Casamino Acids, and Penassay broths; grows well on $0.2 \%$ tryptone; produces growth but no hemolysis on sheep blood agar.

$\mathrm{H}_{2} \mathrm{~S}$, deoxyribonuclease, catalase, oxidase, and phosphatase are produced; the indole, methyl red, Voges-Proskauer, and citrate tests are negative; there is no growth on McConkey or eosin methylene blue. Reduces (denitrifies) $\mathrm{NO}_{3}{ }^{-}$and $\mathrm{NO}_{2}{ }^{-}$to gaseous form; however, much $\mathrm{NH}_{3}$ is present, the significance of which is under investigation.

Habitat. Soil.

Guanine plus cytosine content of the deoxyribonucleic acid. The guanine plus cytosine content of the deoxyribonucleic acid is 37.0 $\mathrm{mol} \%$.

\section{DISCUSSION}

Strain UASM 9D has been assigned to the order Cytophagales on the basis of its gliding motility, lack of fruiting bodies, and low guanine plus cytosine content of its deoxyribonucleic acid. It has been assigned to the genus Flexibacter because it does not degrade polysaccharides (except pectate [weakly] and starch, of which the latter is generally utilized by flexibacters) and does not produce sheaths, microcysts or helical cells. The description of Flexibacter in the eighth edition of Bergey's Manual (4) will have to be broadened slightly because this new organism has thinner cells $(0.3 \mu \mathrm{m}$ compared to $0.5 \mu \mathrm{m})$ and produces a pigment different from those of other flexibacters (4). Strain UASM 9D differs in at least five properties from each of the previously described Flexibacter species (4-8; Table 1), and hence it is proposed that it be regarded as a member of a new species, Flexibacter canadensis (ca na denásis. M.L. adj. canadensis, of Canada, source of the soil from which the organism was isolated). The description of this species is the same as that given above for UASM 9D (= ATCC 29591), the type strain. 


\section{ACKNOWLEDGMENTS}

I am indebted to F. D. Cook, who isolated this organism and who has contributed helpful advice. Thanks are also due to $\mathrm{M}$. Mandel for determining the guanine plus cytosine content of the deoxyribonucleic acid. The financial assistance of the National Research Council of Canada is gratefully acknowledged.

\section{LTERATURE CITED}

1. Christensen, P. J. 1977. Synonymy of Flavobacterium pectinovorum Dorey with Cytophaga johnsonae Stanier. Int. J. Syst. Bacteriol. 27:122-132.

2. Christensen, P. J. 1977. The history, biology, and taxonomy of the Cytophaga group. Can. J. Microbiol. 23: 1599-1653.

3. Christensen, P. J., and F. D. Cook. 1978. Lysobacter, a new genus of non-fruiting, gliding bacteria with a high base ratio. Int. J. Syst. Bacteriol. 28:367-393.

4. Leadbetter, E. R. 1974. Order II. Cytophagales, p. 99121. In R. E. Buchanan and N. E. Gibbons (ed.), Bergey's manual of determinative bacteriology, 8th ed. Williams and Wilkins Co., Baltimore.

5. Lewin, R. A., and D. M. Lounsbery. 1969. Isolation, cultivation, and characterization of flexibacteria. J. Gen. Microbiol. 58:145-170.

6. Soriano, S. 1945. El nuevo order Flexibacteriales y la clasificación de los órdenes de las bacterias. Rev. Argent. Agron. 12:120-140

7. Soriano, S. 1945. Un nuevo order de Bacterias Flexibacteriales. Cienc. Invest. 1:92-93.

8. Soriano, S. 1947. The Flexibacteriales and their systemic position. Antonie van Leeuwenhoek J. Microbiol. Serol. 12:215-222. 